\title{
Can Retail Clinics Save Primary Care?
}

\section{Amer Kaissi*}

Department of Health Care Administration, Trinity University, USA

For the last twelve years, retail clinics have been delivering limitedscope healthcare services in grocery stores, drugstores and general merchandise retailers (such as Wal-Mart, Target, CVS, Walgreens, etc). What seemed like a marginal trend with only 60 clinics in 2005 is now a significant "disruptive innovation" in the healthcare system with 1,357 clinics operating nationwide [1]. Many experts argue that growth is likely to continue in the future. Therefore, it is important to consider the role that retail clinics will play in our primary care system in the next 10-15 years: can the help improve access to basic primary care services as provider shortages worsen and as the healthcare reform law creates a new population of insured patients?

The most important feature of a retail clinic is that care for routine preventative and acute services is provided by a nurse practitioner or physician assistant in a convenient setting that is easily accessible to patients. The cost per visit is much lower than primary care physician offices, urgent care centers and Emergency Rooms, while quality of care and patient satisfaction is as good as or better than in these settings [2-8]. Several factors indicate that the model is here to say: consumer receptiveness is on the rise with $19 \%$ of people reporting having used a retail clinic in 2011 [9], and more and more large healthcare systems are developing their own clinics or affiliating with companies that operate them [10].

Several demand and supply-side factors have contributed to an impending shortage of 46,000 primary care physicians (PCPs) by 2025 [11]. As more baby boomers are turning 65, obesity rates are soaring, and chronic diseases rates are spiraling out of control, less and less medical students are choosing primary care as a specialty of study for financial and other considerations [12]. As a result, more adults are having difficulty in gaining timely access to primary care services, and that is only likely to get worse in the near and long-term future. The Patient Protection and Affordable Care Act (PPACA) passed in 2010 includes several provisions that will increase insurance coverage to an additional 32 million Americans by 2019, but has limited provisions to grow the supply of PCPs. As the Massachusetts experience show, insurance coverage does not necessarily result in access to services.

For retail clinics to play a larger role, several challenges have to be overcome, such as physician opposition, traditional consumer attitudes and financial barriers. While some physicians have embraced retail clinics, many major professional physician associations have criticized and rejected them. A sizable number of patients are still not open to the idea of seeking care at the grocery store, and many clinics have struggled with a financial model that is harder than it seems. Moreover, the supply of nurse practitioners and physician assistants themselves will have to keep up with the increased demand for their services.

These challenges notwithstanding, patients will continue to look for more convenient and less crowded settings to receive care. Since the retail clinic model does not require a physician to be physically present at the clinic (clinics have medical directors that remotely review charts and provide supervision), it represents a possible solution to the access dilemma. Recent studies seem to support this argument: $61 \%$ of retail clinic users do not have a primary care physician, [13], and $30 \%$ of consumers say they would use a retail clinic if it considerably reduced their wait time [9]. However, it remains unclear whether the clinics will remain as just a convenient way for busy insured patients to seek healthcare afterhours and on weekends, or whether they can play a more significant impact in a primary care system on the brink of collapse.

\section{References}

1. Merchant Medicine (2012).

2. Jacoby R, Crawford AG, Chaudhari P, Goldfarb NI (2011) Quality of care for 2 common pediatric conditions treated by convenient care providers. Am J Med Qual 26: 53-58.

3. Mehrotra A, Liu H, Adams JL, Wang MC, Lave JR, et al. (2009) Comparing Costs \& Quality of Care at Retail Clinics With that of Other Medical Settings for 3 Common Illnesses. Ann Intern Med 151: 321-328.

4. Rohrer JE, Angstman KB, Furst JW (2009) Impact of Retail Walk-In Care on Early Return Visits by Adult Primary Care Patients. Qual Manag Health Care 18: $19-24$

5. Rohrer JE, Garrison GM, Angstman KB (2012) Early Return Visits by Pediatric Primary Care Patients with Otitis Media: A Retail Nurse Practitioner Clinic vs. Standard Medical Office Care. Qual Manag Health Care 21: 44-47.

6. Wilson AR, Zhou XT, Shi W, Rodin H, Bargman EP, et al. (2010) Retail Clinics Versus Office Setting: Do Patients Choose Appropriate Providers?. Am J Manag Care 16: 753-759.

7. Harris Interactive.

8. Hunter LP, Weber CE, Morreale AP, Wall JH (2009) Patient Satisfaction With Retail Health Clinic Care. J Am Acad Nurse Pract 21: 565-570.

9. Deloitte Center for Health Solutions (2011) 2011 Survey of Health Care Consumers in the United States.

10. Kaissi A (2010) Hospital- Affiliated and Hospital-Owned Retail Clinics: Strategic opportunities and Operational Challenges. J Healthc Manag 55: 324-337.

11. Bodenheimer T, Pham HH (2010) Primary care: Current problems and proposed solutions. Health Aff (Millwood) 29: 799-805.

12. National Residency Matching Program (2008) Results and Data 2008 main residency match.

13. RAND (2010) Health Care On Aisle 7: the Growing Phenomenon of Retail Clinics.

*Corresponding author: Amer Kaissi, Associate Professor, Department of Health Care Administration, Trinity University, USA, Tel: 210-999-8132; E-mail: akaissi@ trinity.edu

Received May 08, 2012; Accepted May 10, 2012; Published May 12, 2012

Citation: Kaissi A (2012) Can Retail Clinics Save Primary Care? Primary Health Care: Open Access 2:e104. doi:10.4172/2167-1079.1000e104

Copyright: (C) 2012 Kaissi A. This is an open-access article distributed under the terms of the Creative Commons Attribution License, which permits unrestricted use, distribution, and reproduction in any medium, provided the original author and source are credited. 